\title{
ACESSIBILIDADE LINGUÍSTICA E CULTURAL NA EDUCAÇÃO DE SURDOS: A LIBRAS COMO ESTRATÉGIA DIDÁTICA NO ENSINO/PESQUISA/EXTENSÃO $* * *$
}

\author{
ACCESSIBILITY LINGUISTIC AND CULTURAL IN \\ EDUCATION OF THE DEAF: THE LIBRAS AS DIDACTIC \\ STRATEGY IN TEACHING/RESEARCH/EXTENSION
}

\author{
Gláucio de Castro Júnior ${ }^{1}$ \\ Daniela Prometi ${ }^{2}$
}

Recebimento do texto: $14 / 04 / 2018$

Data de aceite: 15/05/2018

RESUMO: Neste artigo, discutiremos as possíveis contribuições acerca da acessibilidade Linguística e Cultural em Língua Brasileira de Sinais (Libras) na educação de Surdos ${ }^{3}$, tendo a Libras como estratégia didática no ensino/pesquisa/extensão, partindo de uma visão mais analítica das propriedades Linguísticas da Libras e do reflexo dessas análises na criação e no registro de sinais termo em Libras de espaços culturais e turísticos de destaque no Brasil. Dessa forma, pretendemos analisar os resultados do projeto "Inventário de Sinais-termo do campo do Patrimônio Cultural em Libras" que buscou a elaboração de um inventário de sinais-termo relativos ao campo do patrimônio Linguístico e Cultural em Libras.

PALAVRAS-CHAVE: Acessibilidade; Patrimônio-Linguístico/Cultural; Sinais-termo; Educação de Surdos; Libras.

ABSTRACT: In this article, we will discuss the possible contributions about the Linguistic and Cultural accessibility in Brazilian Sign Language (Libras) on Deafs ${ }^{3}$ education and didactic teaching strategy teachings/research/extension, starting from a vision more analytical Language properties of the Libras and the reflection of these analyses in the creation and registration of signs-term Libras of cultural spaces and of interest in Brazil. In this way, we intend to analyze the results of the project "Inventory Signs-term of the field of Cultural Heritage in Libras" that sought to prepare an inventory of signs-term relating to the Linguistic and Cultural heritage field in Libras.

KEYWORDS: Accessibility; Linguistic/Cultural heritage; Signs-term; Deaf education; Libras.

\footnotetext{
${ }^{1}$ Doutor em Linguística pela Universidade de Brasília (UnB). Departamento de Linguística, Português e Línguas Clássicas (LIP/UnB). E-mail: librasunb@gmail.com

${ }^{2}$ Mestre e doutoranda em Linguística pela Universidade de Brasília (UnB). Departamento de Linguística, Português e Línguas Clássicas (LIP/UnB). E-mail: danielaprometi@ gmail.com

${ }^{3}$ Destaco o termo Surdo "com S maiúsculo" em pontos estratégicos do texto como uma forma de empoderamento, mostrando minha visão pessoal e enquanto profissional da área, de respeito e de reconhecimento da identidade vivenciada pelos sujeitos Surdos, seus valores linguísticos e sociais, e de todo processo histórico e cultural que os envolve. Vários outros autores também fazem uso dessa mesma estratégia, como por exemplo, Lane (2008. p. 284) e Castro Júnior (2011, p.12).
}

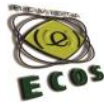




\section{Introdução}

A comunidade Surda está cada vez mais empenhada em discutir o que é ideal para o ensino bilíngue na educação de Surdos. Existem algumas teorias que são u sadas e discutidas nos sistemas educacionais e com as mais recentes observações de Surdos usuários de Língua de Sinais, é claro a falha em alguns sistemas educacionais devido principalmente a falta de uso de recursos didáticos e Linguísticos que não permite uma visibilidade. Por isso, foi preciso buscar uma solução para estes problemas urgentes da falta de acessibilidade Linguística e Cultural.

O projeto do Inventário Nacional de Sinais-termo do Campo do Patrimônio Cultural em Libras é uma atitude interdisciplinar, sob coordenação do professor Gláucio Castro Júnior e desenvolvido no Núcleo de Estudo e Pesquisa da Variação Linguística - Núcleo Varlibras do Departamento de Linguística, Português e Línguas Clássicas - LIP da Universidade de Brasília - UnB, em parceria com o Instituto do Patrimônio Histórico e Artístico Nacional - IPHAN.

O projeto buscou viabilizar os percalços da falta da acessibilidade Linguística e Cultural, e dentre esses problemas, podemos relatar uma situação que motivou pensar o projeto: um aluno Surdo com a primeira língua - L1 sendo a Libras, estudante em uma turma inclusiva, se encontra em uma aula cujo o assunto são: os Patrimônios Histórico Cultural de Florianópolis, a professora que não domina uma metodologia bilíngue planejou em um momento criativo da aula, o uso de vídeos para melhor entendimento do conteúdo, claramente a maioria destes informativos não possuem legendas, dificultando ainda mais o processo educativo com o 
aluno Surdo na inclusão com alunos ouvintes. A partir desta e outras problemáticas, o projeto foi elaborado para suprir a acessibilidade Linguística e cultural ao fornecer vídeos em sua língua materna - Libras, de modo a permitir que os discentes Surdos possam aprender de fato o conteúdo e tornando-o parte importante no ensino-aprendizagem.

Há vários cenários possíveis que este projeto viabilizou na vida de um estudante Surdo, além de conteúdos didáticos, também buscamos permitir o empoderamento das pessoas Surdas em sua primeira língua - L1 - Libras, que é o assunto mais pautado nos últimos anos entre a comunidade acadêmica e a sociedade civil que precisa efetivar uma comunicação bilíngue e atender diferentes mecanismos legais como o decreto de $n^{\circ} 5.626$. Além dos resultados alcançados com os usuários de Libras, o projeto também abrangeu os não-surdos, que tem a Libras como segunda língua L2, de modo que o projeto possibilitou ampliar o vocabulário, por meio de diferentes estratégias didáticas que utilizam a Libras com propriedade para que os professores bilíngues tenham uma efetiva metodologia de trabalho e, assim, se possa ter apropriação deste Inventário Nacional de sinais-termo para melhorar a qualidade de suas aulas.

Essa produção ainda incipiente, no Brasil, é reflexo da própria história dos Surdos, de sua educação, comunidade, cultura, língua e identidade. Os Surdos foram, historicamente, privados de utilizarem a língua de sinais e o uso da Libras foi proibido nos contextos escolares. Tal situação começou a se modificar apenas na segunda metade do século 20 , com os estudos de Stokoe e consonante a esta mudança, se teve o reconhecimento das línguas de sinais. 
Porém, neste artigo, faremos uma breve reflexão acerca da Língua Brasileira de Sinais - Libras que circundam o contexto do seu uso como estratégia didática no ensino/pesquisa/extensão. Quando abordamos a Libras, sinalizamos também o olhar para o registro da Diversidade Linguística e do Patrimônio Literário Nacional, que permite em diferentes momentos as relações Linguísticas através da Libras.

\section{Contextualizando a Língua Brasileira de Sinais - Libras como estratégia didática}

Os estudos que a Linguística da Língua de Sinais tem desenvolvido ao analisar os fenômenos recorrentes na língua têm aos poucos ganhando espaços dentro de alguns compêndios em que os autores Surdos aproveitam as pesquisas na Libras e passam a perceber a necessidade de pesquisar e analisar o que de fato ocorre na Língua. As línguas de sinais são consideradas pela Linguística como línguas naturais ou sistema linguístico legítimo. As Línguas de Sinais conquistaram o status de língua graças aos estudos linguísticos iniciados por Stokoe na década de 1960, embasados na Língua Americana de Sinais. Tais estudos comprovaram que as línguas de sinais atendiam a todos os critérios linguísticos de uma língua genuína: no léxico, na sintaxe e na capacidade de gerar uma quantidade infinita de sentenças. Uma segunda geração de linguistas, representada principalmente por Klima e Bellugi (1979), também contribuíram com dados sobre a fonologia das línguas de sinais e outros aspectos da língua de sinais.

A Libras apresenta diferentes processos Linguísticos e dentre esses

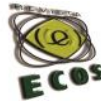


temos o processo de nomeação que resulta no processo de categorização dos termos da Libras. Entende-se por categorização a organização dos termos da Libras feita por um sinalizante de Libras, resultando no registro de diferentes categorias da língua. A categorização compreende também a capacidade de percepção de elementos e traços distintivos entre os referentes percebidos ou apreendidos pelo mecanismo mental do indivíduo Surdo que comunica na modalidade visual-espacial, por meio de características peculiares, sua coexistência com a língua portuguesa e a falta de registros sistemáticos para neologismos, neste caso, de novos nomes próprios.

Em relação às características Linguísticas das Línguas de Sinais, Sacks (1998) diz que a função gramatical é assumida não apenas pelos sinais 'manuais', mas também pelo rosto, pelo espaço e pelo tempo. Os estudos de Stokoe mostraram que os sinais não eram apenas imagens para nomear os sinais, mas símbolos abstratos complexos, com uma complexa estrutura interior. Ele foi o primeiro a analisar os sinais e a pesquisar suas partes. Ele comprovou que cada sinal apresentava pelo menos três partes independentes: a locação (ou ponto de articulação), a configuração de mãos e o movimento. Na sequência dos estudos tivemos descritas cada uma das unidades mínimas da Libras e de acordo com Quadros e Karnopp (2004) temos: Configuração de mão (CM), Movimento (M), Ponto de Articulação (PA), Orientação da mão (OR) e Expressões não-manuais (NM).

As línguas de sinais, por comprovação científica, cumprem todas as funções de uma língua natural, mesmo assim ainda sofrem preconceito e são desvalorizadas diante das línguas orais, sendo consideradas como uma 
derivação da gestualidade espontânea, como uma mescla de pantomima e sinais icônicos.

O pesquisador Surdo Castro Júnior (2009), defende que, existe as representações paramétricas na produção de diversos sinais-termo na Libras, como o movimento, a direção, a configuração de mão, a orientação, as expressões faciais e não-manuais que caracteriza a produção e a construção mental do sinal-termo. Pois, são os parâmetros linguísticos da Libras que possibilita a formação e realização do sinal-termo e assim desencadear os processos nos diversos níveis sintáticos, semântico, fonológico e morfológico na gramática da Libras.

Com isso, não se pode limitar a criação, a formação e a conceituação dos sinais-termo apenas à forma ou a representação visual do sinal-termo, é preciso analisar também a construção mental para que se possa caracterizar a Libras como uma língua de modalidade visual-espacial. Isto se dá porque essas línguas são independentes das línguas orais, pois foram produzidas dentro das comunidades Surdas.

Vale ressaltar ainda que não há uma equivalência dos sinais-termo com a Língua Portuguesa, ou seja, não podemos em hipóteses algumas querer encontrar todos os sinais-termos para cada palavra em português. Isso significa que um sinal pode ter um significado representado por uma ou mais palavras em português. O contrário também é verdadeiro, onde uma palavra ou significado do português pode ser representado por um sinaltermo em Libras. Portanto, sinônimos de palavras associadas aos sinaistermo podem ser usados adequadamente.

Por exemplo, as palavras CANTAR, MÚSICA, CÂNTICO, 
CANTAROLAR e outros sinônimos serão todos representados por um sinal em Libras, o sinal de MÚSICA. Da mesma forma, as palavras BELO, BONITO E BELEZA e outros sinônimos serão todos representados por um sinal-termo em Libras, o sinal BONITO. Assim sendo, os sinais-termo são bastantes abrangentes e possuem muitos significados mais amplos e não se limita apenas para a iconicidade que o aprendiz da Libras precisará, principalmente com o contato com Surdos sinalizantes de Libras entender corretamente estes mecanismos. No item seguinte apresentamos a discussão sobre as especificidades das pessoas Surdas e a acessibilidade na promoção do direito Cultural e Linguístico.

\section{Pessoas Surdas e a acessibilidade: uma questão de direito cultural}

As atividades de lazer e cultura, assim como qualquer outro setor de uma sociedade que defende a equiparação de oportunidades para todos, precisam ser adequadas às necessidades especiais de um expressivo número de pessoas com algum tipo de deficiência ou alguma especificidade, a fim de que todos tenham assistidos os seus direitos ao lazer e à qualidade de vida.

Recentemente, no ano de 2017 o Exame Nacional do ensino Médio - ENEM teve pela primeira vez a prova em vídeolibras com tradução e interpretação para a Libras das questões do ENEM e a prova teve alguns objetivos que podemos listar: analisar, interpretar e aplicar recursos expressivos das linguagens, relacionando textos com seus contextos, mediante a natureza, função, organização e estrutura das manifestações, de 
acordo com suas condições de produção e recepção e das relações entre o texto literário e seu momento de produção, situando aspectos do contexto histórico, social e político, bem como das relações sobre concepções artísticas e procedimentos de construção do texto literário. Tratam, ainda, do reconhecimento da presença de valores sociais e humanos atualizáveis e permanentes no patrimônio literário nacional e reconhecer a importância do patrimônio linguístico para a preservação da memória e da identidade nacional.

Apesar dessa conquista, é preciso considerar a pessoa Surda em suas reivindicações do acesso a educação bilíngue e que as pessoas Surdas talvez sejam um dos segmentos que efetivamente careçam da falta de uma educação acessível, do acesso ao ensino da Literatura em Libras, que acarreta na falta de leitura por parte dos estudantes Surdos e o desconhecimento do patrimônio Linguístico e Literário Nacional. Essa lacuna determina várias consequências como o prejuízo linguístico, a falta de produtividade na língua, a aquisição do saber em Libras, o desdobramento do processo de comunicação na modalidade visual-espacial na expressão dos anseios pessoais, sociais, culturais, religiosos, didáticos, psicológicos, dentre outros que comprometem atingir os valores ideais que se espera por meio da educação e principalmente através da língua e da Literatura. Por isso, é urgente a busca de medidas eficazes de acessibilidade para as pessoas Surdas.

Sassaki (2002) apresenta algumas barreiras que de alguma forma ou de maneira geral, impossibilitam o acesso ao lazer e cultua por parte das pessoas com necessidades especiais, acesso aos logradouros turísticos (bens

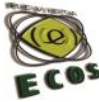


e serviços) de lazer e recreação. Enumeraremos as seis barreiras apresentadas pelo autor:

(1) Barreiras arquitetônicas nos aeroportos, terminais rodoviários, espaços urbanos, hotéis e similares, museus, teatros, transportes coletivos, parques ecológicos, parques temáticos, locais de eventos, acampamentos, etc.;

(2) Barreiras atitudinais na sociedade como um todo e, especialmente, em relação a profissionais com poder de decisão política, mas ainda preconceituosos a respeito das pessoas com deficiência, e que por isso deixam de abrir oportunidades turísticas para elas;

(3) Barreiras comunicacionais nas sinalizações de locais (ignorando as pessoas cegas) e na não contratação de intérpretes de língua de sinais entre os guias de turismo e os recepcionistas nos locais de maior atração turística;

(4) Barreiras metodológicas na forma tradicional, através da qual os agentes de viagens e os promotores de atrações turísticas locais estabelecem propostas e acordos com os turistas, tanto os efetivos como os em potencial;

(5) Barreiras instrumentais nos aparelhos, equipamentos, ferramentas e outros dispositivos que fazem parte dos locais visitados por turistas e que tradicionalmente ignoram as limitações físicas, sensoriais e mentais de algumas das pessoas com deficiência.

(6) Barreiras programáticas existentes nos decretos, leis, regulamentos, normas, políticas públicas e outras peças escritas, barreiras estas invisíveis, não explícitas, mas que, na prática, impedem ou dificultam, para certas pessoas, a utilização dos serviços e bens turísticos.

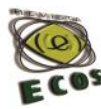


O que se busca defender, a partir dessa realidade, é uma implementação de medidas de acessibilidade que atuem na contramão destas barreiras. Para tanto, trataremos de conceituar o termo acessibilidade, de acordo com os princípios da inclusão. Alguns dicionários apresentam o conceito de acessibilidade como: "(do latim: accessibilitate) 1. Facilidade de acesso, de obtenção. 2. Facilidade no trato" (MODERNO DICIONÁRIO DA LÍNGUA PORTUGUESA - MICHAELIS, 2000, p.37); “1. Qualidade ou caráter de acessível. 2. Facilidade na aproximação, no trato ou na obtenção.” (NOVO DICIONÁRIO DA LINGUA PORTUGUESA AURÉLIO, 2009, p. 22).

Acessibilidade é definida pela ABNT-Associação Brasileira de Normas Técnicas, pela norma NBR 9050/94 - “Acessibilidade de pessoas portadoras de deficiências a edificações, espaço mobiliário e equipamentos urbanos", como sendo a possibilidade e condição de alcance para utilização, com segurança e autonomia, de edificações, espaço, mobiliário e equipamento urbano.

Significa, assim, não apenas permitir que pessoas com deficiências participem de atividades que incluem o uso de produtos, serviços e informação, mas a inclusão e extensão do uso destes por todas as parcelas presentes em uma determinada população. Na arquitetura e no urbanismo, a acessibilidade tem sido uma preocupação constante, nas últimas décadas.

Tal conceito está ligado à qualidade de projetos, baseando-se num conjunto de especificações, de normas, de legislação e, principalmente, em conscientização e sensibilização dos profissionais, para que estabeleçam

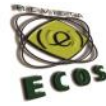


exigências mínimas a serem observadas para acessibilidade, tanto dos espaços edificados como de atendimento aos serviços, quer seja de domínio privado ou público. E é justamente no contexto dos serviços de reabilitação, saúde, educação, transporte, mercado de trabalho e ambientes físicos internos e externos, que o termo ‘acessibilidade' veio se desenvolvendo nos últimos anos. Com o advento do paradigma da inclusão e do conceito de diversidade, têm-se, portanto, a valorização do ser humano em todos os setores sociais comuns, tornando a acessibilidade não mais limitada às questões arquitetônicas.

Ao tratar da acessibilidade, objetivando o combate às barreiras já apresentadas, Sassaki (2003) atribui especificidades para o acesso que devem existir a todas as pessoas, sejam deficientes ou não, com respeito ao direito que todos têm de circular, de ir e vir. Sendo assim, atualmente obrigatórias por lei, por consequência do paradigma da inclusão, acessibilidade caracteriza-se como:

(1) Acessibilidade arquitetônica: sem barreiras ambientais físicas, nas escolas, nas empresas, nas residências, nos edifícios públicos, nos centros de convenções, nos espaços urbanos, nos equipamentos urbanos, nos locais de lazer e turismo e nos meios de transporte individual ou coletivo.

(2) Acessibilidade comunicacional: sem barreiras na comunicação interpessoal (face-a-face, língua de sinais, linguagem corporal, linguagem gestual, e outros meios), na comunicação escrita (jornal, revista, livros, cartas, apostilas, etc., incluindo textos em braile, textos com letras ampliadas para quem tem baixa visão, notebook e outras tecnologias

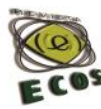


assistivas para comunicar) e na comunicação virtual (acessibilidade digital).

(3) Acessibilidade metodológica: sem barreiras nos métodos e técnicas de estudo (adaptações curriculares, aulas baseadas nas inteligências múltiplas, uso de todos os estilos de aprendizagem, participação do todo de cada aluno, novo conceito de logística aplicada), de trabalho (métodos e técnicas de treinamento e desenvolvimento de recursos humanos, ergonomia, novo conceito de fluxograma, empoderamento), de ação comunitária (metodologia social, cultural, artística, dentre outras, baseada em participação ativa), de educação dos filhos (novos métodos e técnicas nas relações familiares, etc.) e de outras áreas de atuação.

(4) Acessibilidade instrumental: sem barreiras nos instrumentos e utensílios de estudo (lápis, caneta, transferidor, régua, teclado de computador, materiais pedagógicos), de trabalho (ferramentas, máquinas, equipamentos), de atividades da vida diária (tecnologia assistiva para comunicar, fazer higiene pessoal, vestir, comer, andar, tomar banho, etc.), de lazer, esporte e recreação (dispositivos que atendam às limitações sensoriais, físicas e mentais, etc.) e de outras áreas de atuação (grifo nosso).

(5) Acessibilidade programática: sem barreiras invisíveis embutidas em políticas públicas (leis, decretos, portarias, resoluções, medidas provisórias, etc.), em regulamentos (institucionais, escolares, empresariais, comunitários etc.) e em normas de um modo geral.

(6) Acessibilidade atitudinal: sem preconceitos, estigmas, estereótipos e discriminações, como resultado de programas e práticas de sensibilização e de conscientização das pessoas em geral sobre a convivência na diversidade humana. 
Quando pensadas as políticas públicas enquanto ações e normas do poder público que regem a legitimidade da cidadania e da acessibilidade, recorremos à busca de algumas leis que possibilitem a contribuição para esta realidade da inclusão efetiva - realidade esta calcada no reconhecimento da diferença e em uma revolução conceitual que conceba uma sociedade em que todos sejam partícipes, com direito de igualdade, levando em consideração as suas características próprias, sua alteridade. Em princípio, tomaremos como pano de fundo para esta discussão, as diretrizes traçadas referentes ao Direito ao Lazer. Embora o lazer seja previsto na Constituição Federal, no artigo $6^{\circ}$ como um direito social, assim como a educação, a saúde, a moradia e a segurança, ele não tem sido foco nos espaços de discussões. Porém, o direito ao lazer é tão fundamental para o pleno exercício da cidadania como os demais apresentados acima (SASSAKI, 2003).

Para as pessoas Surdas essa realidade não é diferente, pois grande parte dessa população tem tal direito subtraído, seja pela própria família, num ato consciente de superproteção, seja pelos órgãos públicos, que não zelam suficientemente pela observância das normas de acessibilidade nos bens e serviços prestados. Tal acessibilidade, como já dito, passa pela questão comunicacional e de atitude, direitos que, uma vez subtraídos, podem diminuir ou anular o acesso à informação - muito reclamado, porém, um tanto utópico no que tange à deficiência sensorial (surdez e cegueira).

O Estatuto da Cidade, Lei 10.257/01, artigo $1^{\circ}$, insere o lazer como um dos elementos indispensáveis para a garantia do direito a cidades sustentáveis para as presentes e futuras gerações. A Lei 8.080/90, no artigo 
$3^{\circ}$, pressupõe que o lazer é também um dos fatores determinantes e condicionantes da saúde. O artigo $4^{\circ}$ do Estatuto da Criança e do 69 Adolescente diz que é dever da família, da comunidade, da sociedade em geral e do Poder Público assegurar, com absoluta prioridade, a efetivação dos direitos referentes à vida, à saúde, à alimentação, à educação, ao esporte e ao lazer, à profissionalização, à cultura, à dignidade, ao respeito, à liberdade e à convivência familiar e comunitária.

Já a Lei 7.853, de 24/10/89, dispõe sobre a Coordenadoria Nacional para Integração da Pessoa Portadora de Deficiência (Corde) que é, atualmente, o órgão da Secretaria Especial de Direitos Humanos responsável por tratar dos direitos das pessoas com deficiência à saúde, à educação, ao trabalho, ao lazer, à previdência social e ao amparo à infância e à maternidade.

Diante desta legislação vigente, em caso de desrespeito aos direitos estabelecidos no quanto aos assuntos de acessibilidade ao lazer e patrimônio cultural, cabe ao Ministério Público cuidar, fiscalizar e fazer cumprir as determinações legais, de interesse local, adaptando praças e parques, eliminando obstáculos arquitetônicos, expedindo alvarás de funcionamento só após verificar se o estabelecimento cumpre as normas de acessibilidade (art.30, CF/88).

O Ministério do Turismo produziu no ano de 2008 um documento, a partir do Manual de Recepção e Acessibilidade de Pessoas com Deficiência a Empreendimentos e Equipamentos Turísticos, publicado pela Embratur, de acordo com a legislação brasileira e Normas Técnicas ABNT. Tal documento reconhece que o turismo com enfoque social vem se

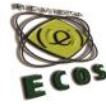


desenvolvendo acentuadamente no mundo, de modo especial, no que se refere ao acesso à experiência turística para as pessoas com deficiência e com mobilidade reduzida. Apresentamos tais documentos em anexo, pois se referem ao atendimento prioritário para pessoas com deficiência.

É importante salientar que, mesmo diante das leis apresentadas, embora pudessem existir outras ainda mais específicas, o simples fato de ser garantido o direito fundamental de ir e vir a todos, já é um embasamento suficiente para que sejam adotadas as medidas necessárias, no sentido de permitir que pessoas com deficiência exerçam tal direito em plenitude (art. $\left.5^{\circ}, \mathrm{CF} / 88\right)$.

A Constituição é nitidamente promissora de princípios que visam a inclusão social. Além de garantir o direito à igualdade, à não-discriminação, elege também como objetivos fundamentais da República Federativa do Brasil (art. $3^{\circ}$ ): a construção de uma sociedade livre, justa e solidária; garantir o desenvolvimento nacional; reduzir as desigualdades sociais; promover o bem de todos, sem preconceitos (SASSAKI, 2003).

Para possibilitar o acesso ao lazer, por exemplo, algumas medidas nos servem como fontes ou parâmetros para embasar os requisitos de acessibilidade. Para tanto, além dos requisitos referentes à eliminação das barreiras arquitetônicas (edifícios, espaços, mobiliários, equipamentos urbanos, etc.), destacaremos alguns dos requisitos referentes à prioridade de atendimento: a valorização da língua de sinais (Lei 10.048/2000; a lei de Libras - Língua Brasileira de Sinais - 10.436/02) e a legenda oculta - closed caption (Lei 10.098/00), que trata da eliminação de barreiras de comunicação na programação televisiva.

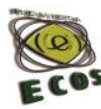


$\mathrm{O}$ atendimento prioritário às pessoas com deficiência compreende tratamento diferenciado/imediato, dentre os quais destacamos os já referidos: I - assentos adequados, espaços e instalações acessíveis; II Serviços de atendimento para pessoas com deficiência auditiva/surdos prestado por intérpretes da Língua Brasileira de Sinais (Libras) e, para pessoas surdocegas, prestado por guias-intérpretes.

A Libras, como já apresentada, e conforme definida pela própria Lei $\left(\operatorname{art.~} 1^{\circ}\right)$, é a forma de comunicação e expressão dos Surdos, que apresenta um sistema Linguístico de natureza visual-espacial, com estrutura gramatical própria.

Compreende-se que os Surdos não apresentam restrições físicas quanto à sua locomoção, mas as barreiras em sua comunicação, geradas pela falta de audição, constituem o sério entrave para possam usufruir de seus direitos linguísticos e literários. Logo, a grande e primeira forma de atenuar tal limitação, que compromete também o acesso aos espaços sociais, seria proporcionar nos ambientes como cinemas, restaurante, hotéis, hospitais, postos policiais, bancos, centros de compras, parques, dentre outros locais de acesso ao público, a presença de profissionais treinados a atender, de forma minimamente eficaz, pessoas Surdas através da Libras e/ou outros recursos tecnológicos que permitam o acesso às informações Linguísticas e Literárias.

A Lei 10.436/02, em seu art. $3^{\circ}$, é categórica no sentido de que as instituições públicas e empresas concessionárias de serviços públicos de assistência à saúde devem garantir atendimento e tratamento adequado aos 
deficientes auditivos, o que inclui pessoas que tenham, pelo menos, conhecimentos básicos de Libras.

A Lei n 323/2001, do município de São Paulo, além de determinar o ensino da Libras a todos os alunos das redes municipais de ensino, ainda amplia o uso da Língua de Sinais para a completa acessibilidade dos Surdos, utilizando-se sempre da sinalização visual, em conjunto com os avisos sonoros, por exemplo: campainhas que indicam a saída de veículos de garagens devem ser acompanhadas de sinal luminoso, ou outro; o mesmo em elevadores; em locais fechados, quanto ao aviso de incêndio ou outro perigo; em motéis e hotéis, a campainha luminosa para anunciar a chegada de alguém.

Outro aspecto incluso nos serviços turísticos, que podem apresentar especificidades para as comunidades Surdas, são os serviços de telecomunicações, podendo dispor de um serviço especial STFC (Serviço Telefônico Fixo Comutado), disponível para uso do público em geral:

a) Instalar, em âmbito nacional e em locais públicos, telefones de uso público adaptados para uso por pessoas Surdas;

b) Garantir a disponibilidade de instalação dos STFC para acessos residenciais; e,

c) Garantir a existência de centrais de intermediação de comunicação telefônica, a serem utilizadas pelos Surdos, em todo o território nacional.

Há informações que dão conta da existência do sistema telefônico adaptado para o uso dos Surdos, já instalado em todos os aeroportos do 
território nacional - isso demonstra o cumprimento deste requisito de lei por parte de um serviço turístico.

Apresentadas algumas das definições legais que, se aplicadas, auxiliam nos processos inclusivos da e na sociedade, compreendemos que as barreiras comunicacionais tornam-se agravantes quando associados às barreiras atitudinais, resultando no fato de as pessoas que possuem uma diferença, serem vistas como anormais, deficientes, incapazes, não sendo vistas como titulares dos mesmos direitos que a maioria.

Essas barreiras se apresentam no fato de os programas de acessibilidade para pessoas com deficiência serem destinados apenas a locais que alguns consideram mais viáveis economicamente/politicamente. Não se observa que 'esses' cidadãos também são sujeitos de desejos e de possibilidades de vivências e experiências Culturais e Linguísticas.

A seguir, apresentamos alguns sinais-termo do espaço turísticos da cidade de Brasília, selecionamos os sinais-termo do Campo do Patrimônio Cultural que representam alguns espaços públicos e turísticos que são resultados do projeto do Inventário de Sinais-termo do campo do Patrimônio Cultural em Libras e que permite ampliar as discussões: 
Figura 1- PONTE JUSCELINO KUBITSCHEK

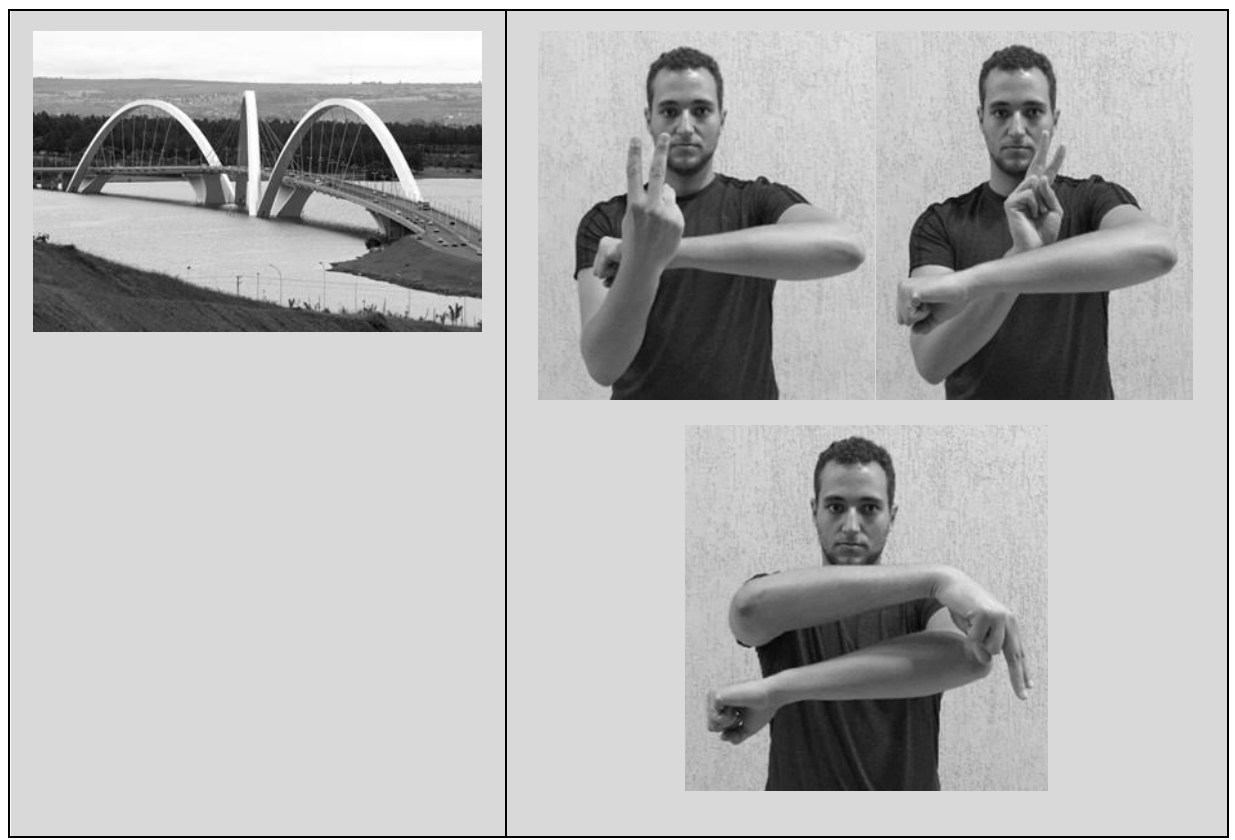

Fonte: Elaborado pelos autores deste artigo.

Figura 2- MEMORIAL JK

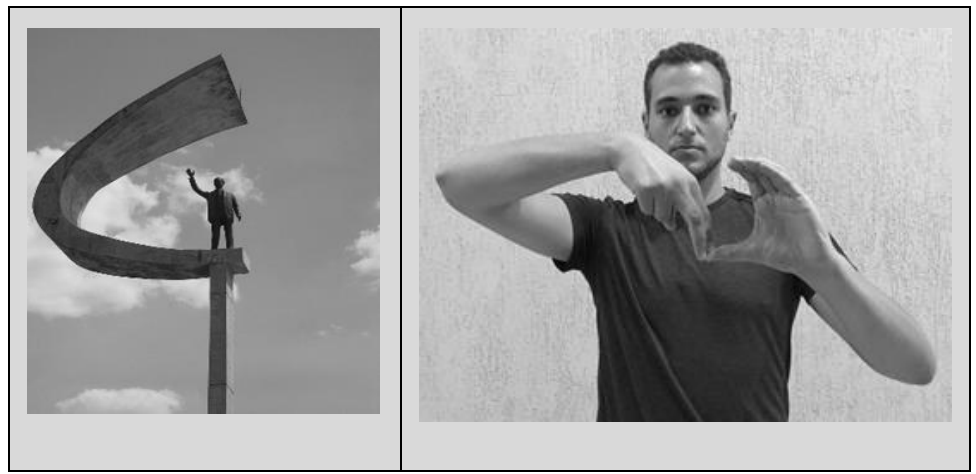

Fonte: Elaborado pelos autores deste artigo.

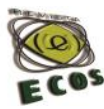


ISSN: $2316-3933$

Online

REVISTA ECOS

Programa de Pós-graduação em Estudos Literários/ UNEMAT

Programa de Pós-graduação em Linguística/ UNEMAT

Centro de Estudos e Pesquisas em Literatura

Centro de Estudos e Pesquisas em Linguagem

Figura 3- MUSEU NACIONAL HONESTINO GUIMARÃES

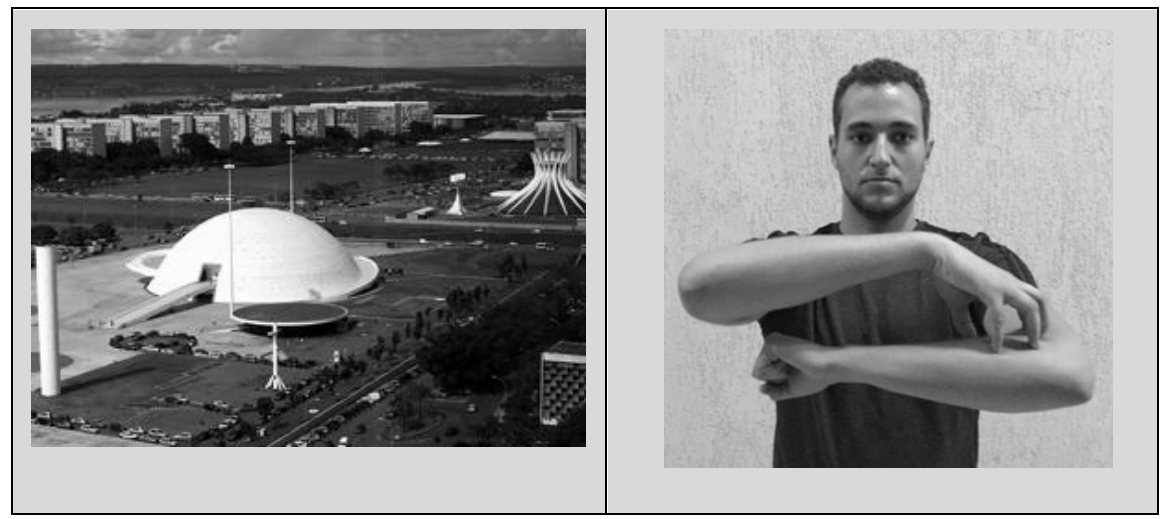

Fonte: Elaborado pelos autores deste artigo.

Figura 4- TORRE DE TV DIGITAL DE BRASÍLIA

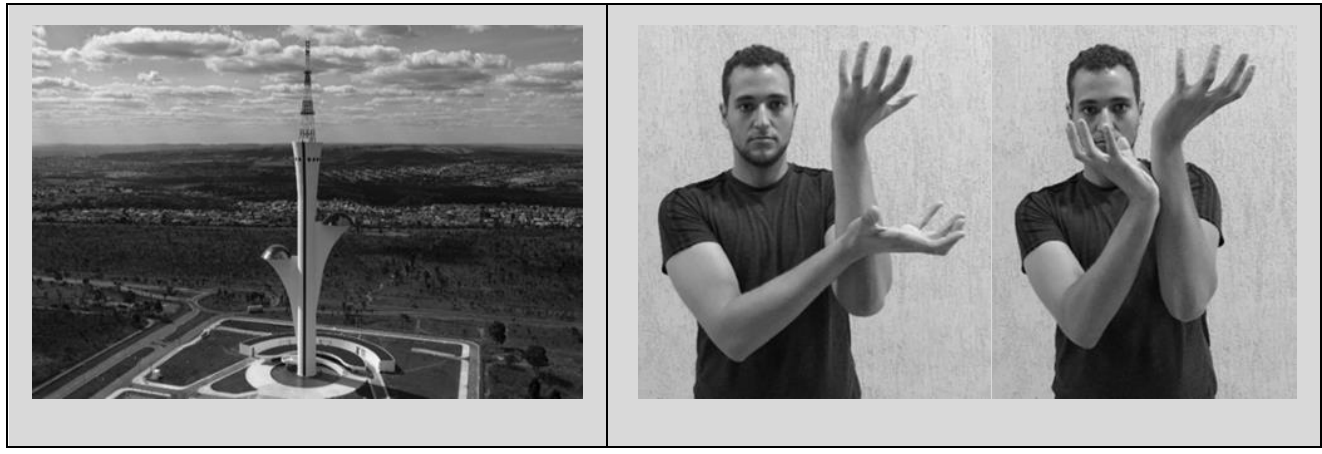

Fonte: Elaborado pelos autores deste artigo.

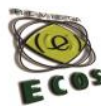


Figura 5- CATEDRAL METROPOLITANA DE BRASÍLIA

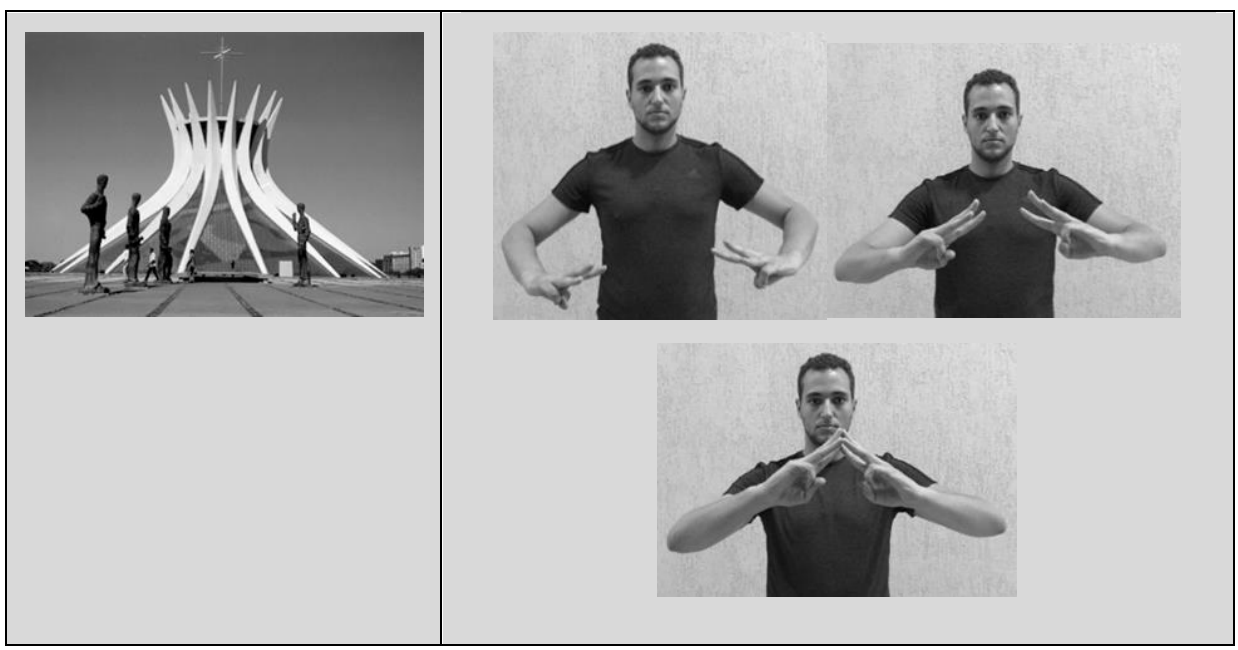

Fonte: Elaborado pelos autores deste artigo.

Figura 6 - TORRE DE TV DE BRASÍLIA

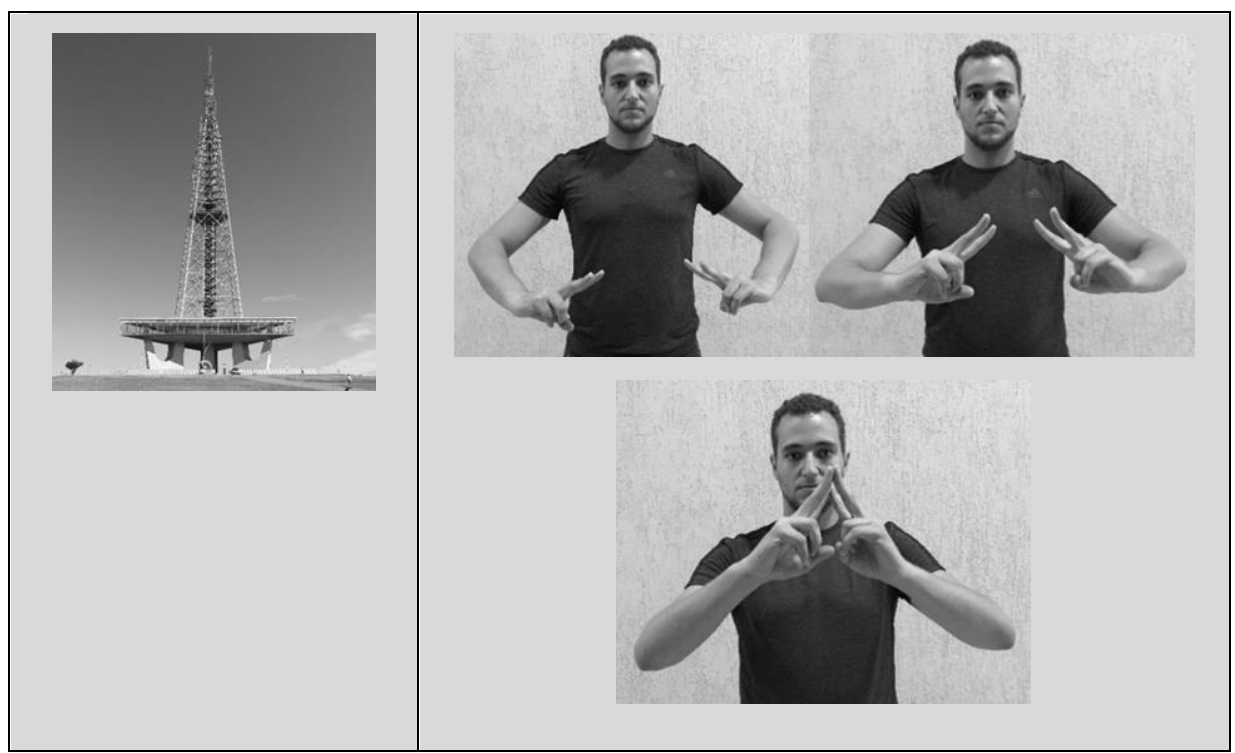

Fonte: Elaborado pelos autores deste artigo.

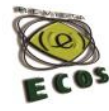


Figura 7 - TEATRO NACIONAL CLÁUDIO SANTORO

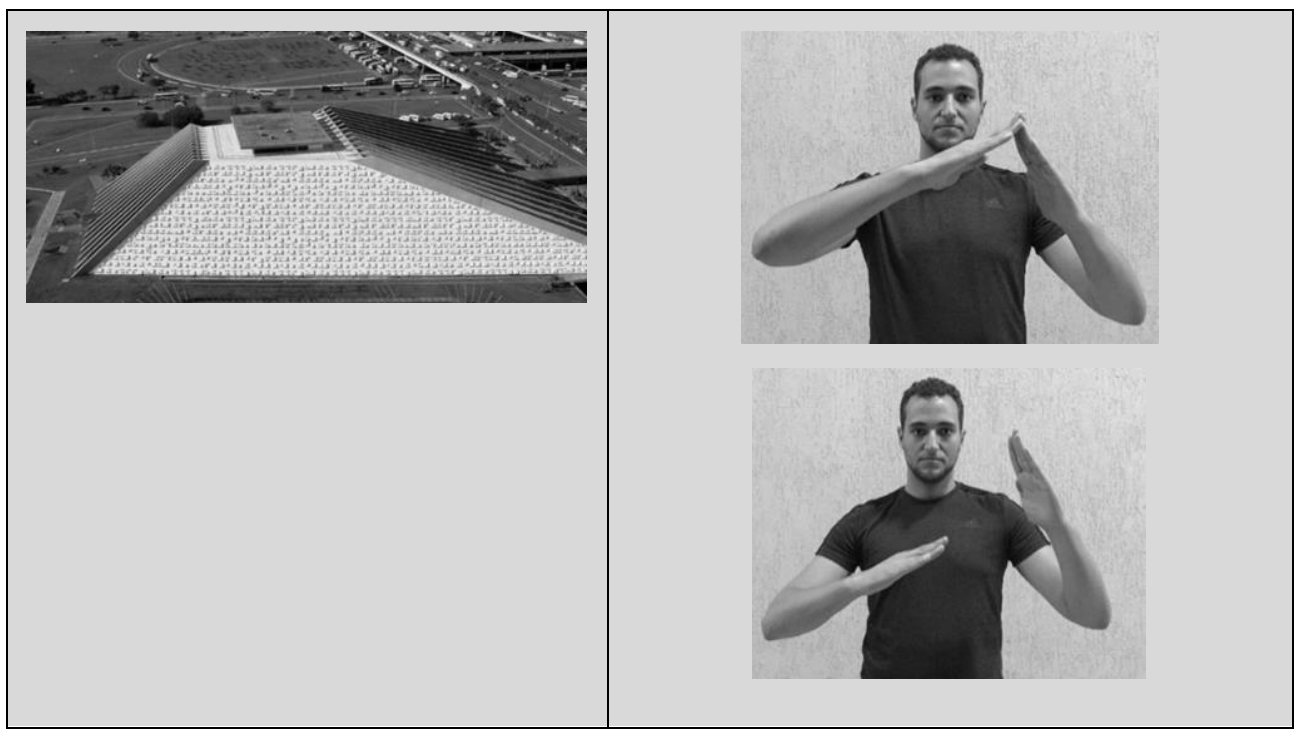

Fonte: Elaborado pelos autores deste artigo.

Assumindo a Libras como uma língua produtiva e em processo de nomeação, acreditamos que seja possível pensar nas contribuições da teoria da Linguística da Língua de sinais, para o ensino/pesquisa/extensão da Libras. Desta perspectiva, percebemos que a apresentação de sinais-termo de locais turísticos e culturais permite promover uma tentativa válida de reflexão sobre a didática no uso da Libras que, por sua vez, poderá deflagrar o conhecimento de termos novos e ou conhecidos pelas pessoas Surdas em diversas situações comunicativas. Assim, o registro da Libras permite que se tenham mecanismos didáticos e que a Libras seja a língua de acesso aos termos Linguísticos e culturais na educação de Surdos. No item seguinte 
apresentamos o Inventário Nacional de Sinais-termo do Campo do Patrimônio Cultural em Libras.

\section{O Inventário Nacional de sinais-termo do Patrimônio Cultural do Brasil em Libras}

A Libras é a Língua de Sinais Brasileira reconhecida pela Lei de número 10.436 de 24 de Abril de 2002. A partir do contato dos alunos de graduação e da comunidade acadêmica com a língua por meio da Libras, observamos a riqueza de conhecimento contida na sua aprendizagem e na comunicação com o Surdo. Constatou-se a dificuldade dos ouvintes em aprender a Libras. A Libras de fato é um instrumento fundamental para o desenvolvimento e a inserção do Surdo na sociedade com o estudante de graduação, da pós-graduação e da comunidade acadêmica de um modo geral que fala a Língua Portuguesa. Ao oportunizar a extensão por meio da Libras, é possível aprimorar e desenvolver o aprendizado da Libras, por meio do uso de ferramentas e de instrumentos da comunicação.

O Projeto Inventário de Sinais-termo do Campo do Patrimônio Cultural em Libras buscou desenvolver o aprendizado da Libras por meio da utilização de ferramentas das tecnologias da informação e da comunicação e contribuir com a acessibilidade acadêmica na Universidade de Brasília - UnB, proporcionando que a acessibilidade seja o meio de inclusão de estudantes ouvintes e Surdos na vida acadêmica e social por meio do projeto de extensão. 
Inicialmente o projeto foi aplicado e desenvolvido no Rio de Janeiro e a partir dos resultados foi possível contemplar e realizar este projeto na região do Centro-oeste, e por isso, elegemos a cidade de Brasília no Distrito Federal e a cidade de Alto Paraíso em Goiás pelos motivos que seguem: em 1972, a UNESCO - Organização das Nações Unidas para a Educação, a Ciência e a Cultura - criou a Convenção do Patrimônio Mundial, para incentivar a preservação de bens culturais e naturais considerados significativos para a humanidade. O objetivo é permitir que o legado que recebemos do passado, e vivemos no presente, possa ser transmitido às futuras gerações.

O conceito de Patrimônio Cultural da Humanidade encerra o entendimento de que sua aplicação é universal. Os sítios do Patrimônio Mundial pertencem a todos os povos do mundo, independentemente do território em que estejam localizados. Marco da arquitetura e urbanismo modernos, Brasília é detentora da maior área tombada do mundo - 112,25 $\mathrm{km}^{2}$ - e foi inscrita pela UNESCO na lista de bens do Patrimônio Mundial em 7 de dezembro de 1987, sendo o único bem contemporâneo a merecer essa distinção.

O Patrimônio cultural de Brasília é composto por monumentos, edifícios ou sítios que tenham valor histórico, estético, arqueológico, científico, literário, etnológico ou antropológico, e a compreensão da sua preservação reafirma a necessidade de se executar políticas públicas capazes de assegurar a proteção desse patrimônio.

Para isso, foi necessário conhecer a cultura e as especificidades Linguísticas, literárias e históricas do Surdo, dessa forma, foi preciso

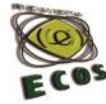


entender que a surdez, exige as experiências visuais e fornece ao sujeito Surdo as condições de constituir sua subjetividade por meio de experiências cognitivo-linguísticas, mediadas por formas de comunicação simbólica e alternativa, as quais encontram na língua de sinais seu principal meio de concretização.

O presente projeto mostrou o quanto a universidade e as instituições de ensino, de um modo geral, precisa incentivar a valorização de uma forma de comunicação que de fato aproxime os indivíduos na aplicação prática e social do aprendizado da segunda língua oficial do Brasil - Libras, com possibilidades de executar o projeto a nível nacional em uma perspectiva a longo prazo. O que acontece com o Surdo e com os alunos que aprendem Libras é reflexo de uma realidade muito abrangente: as relações de poder e domínio de grupos majoritários sobre grupos minoritários.

A esperança é ver que pelo menos, no que diz respeito à realidade dos Surdos e da comunidade acadêmica que aprendem Libras, as discussões e iniciativas estão acontecendo em sentido mais progressivo e que caminhe em busca da efetiva divulgação da Libras e possibilitar de fato um retorno à população de produtos tecnológicos e serviços em Libras.

No item seguinte, apresentamos os procedimentos metodológicos e didáticos que são cruciais para o desenvolvimento do Inventário Nacional de Sinais-termo do Campo do Patrimônio Cultural em Libras em larga escala de modo a ser utilizado para a promoção do ensino/pesquisa/extensão por meio da Libras. 


\section{Procedimentos metodológicos do registro do Inventário Nacional de sinais-termo do Campo do Patrimônio Cultural em Libras}

O projeto sob coordenação de Gláucio Castro Júnior, pesquisador Surdo, iniciou-se no ano de 2015 e está em processo de consolidação e desenvolvimento pelas instituições participantes e financiadoras. A metodologia desenvolvida no projeto teve como base a necessidade de utilizar os recursos tecnológicos e da informação disponíveis para a Libras, bem como os estudos de Léxico e Terminologia de Castro Júnior orientado por Faulstich (2014).

Inicialmente foi desenvolvido o projeto-piloto 'Acessibilidade de Comunicação, Tradução e Interpretação para a Libras do Aplicativo Portal do Patrimônio' cujo objetivo foi fomentar a colaboração de pesquisadores e especialistas no campo de pesquisa científica da Linguística da língua de sinais, de modo a contribuir para o registro da Diversidade Linguística da Libras e permitir a acessibilidade dos Surdos às informações contidas no Aplicativo Portal do Patrimônio, disponível no sistema IOS e Android para tablets e telefones celulares.

Deste modo, a equipe de tradutores e intérpretes que compõe a equipe do Inventário Nacional de Sinais-termo do Patrimônio Histórico e Artístico Nacional do Brasil em Libras sob a coordenação do pesquisador professor Dr. Gláucio Castro Júnior se deslocou para o Estado do Rio de Janeiro para a sede do Instituto do Patrimônio Histórico e Artístico Nacional - IPHAN e iniciaram a gravação em Libras de 16 (dezesseis) textos e o 
projeto obteve êxito e por isso permitirá o desenvolvimento de outras atividades do projeto em outras regiões.

Assim, o projeto contou com três fases, a primeira fase trata da concepção e planejamento do projeto. Esta primeira fase envolveu a apresentação da equipe e dos colaboradores. Um dos critérios essenciais para a constituição do Inventário de Sinais-termo em Libras é o envolvimento de Surdos nas diversas etapas do processo. Nas pesquisas Linguísticas, sabemos que os sinalizantes tendem a não utilizar a variante Linguística da língua diante de interlocutores e fatores externos à língua. Por esse motivo, um aspecto metodológico crucial do projeto foi o convite a Surdos participativos nas comunidades Surdas.

Em longo prazo, o projeto poderá contemplar todas as regiões do Brasil nas 27 capitais brasileiras. Hoje, em decorrência das determinações do Decreto $n^{\circ} 5.626$ - que determina o ensino de Libras a alunos dos cursos de licenciatura, fonoaudiologia, pedagogia e educação especial tivemos o ingresso de professores Surdos efetivos em universidades públicas do país. Inclusive, na Universidade de Brasília - UnB, tivemos o ingresso de nove professores Surdos, e estes professores são colaboradores do projeto e inclusive utilizam-se da infra-estrutura da Universidade de Brasília - UnB, principalmente o Núcleo de Ensino e Pesquisa da Variação Linguística da Libras - Núcleo Varlibras, além deste espaço, temos também o Pólo da Universidade de Brasília - UnB em Alto Paraíso em Goiás que também oferece toda infra-estrutura necessária para o desenvolvimento do projeto.

Além disso, o coordenador da pesquisa e os professores de Libras fortalece o ensino da Libras com propriedade, na aplicação nos processos 
de ensino/aprendizagem/extensão de conhecimentos e produtos que poderão ser utilizados por meio do inventário constituído para o desenvolvimento de materiais didáticos para o ensino de Libras na universidade.

Foram buscadas alternativas com outros líderes Surdos locais para consolidar o projeto. A segunda fase da pesquisa foi a execução do projeto, de abril a setembro de 2016, com carga horária de 400 horas, os participantes deste projeto precisou atender alguns critérios: i) estar adquirindo a Libras; ii) Surdos com diferentes graus de escolarização (ensino fundamental, ensino médio e ensino superior completo). iii) profissionais que atuam na educação de Surdos. Por fim, só foram incluídos como informantes no projeto aqueles Surdos que consentirem sem quaisquer restrições a todas as condições de uso e distribuição de suas imagens, tal como definido no Termo de Participação em Pesquisa a ser elaborado na primeira fase.

Os participantes do projeto passou por uma consultoria técnica e de capacitação continuada para a produção de material acadêmico - Léxico alfabético de sinais-termo do campo do patrimônio cultural em Libras para a inserção dos dados no aplicativo "Portal do Patrimônio", por isso todos os dados coletados serão armazenados em no mínimo três versões: uma em servidor específico do inventário de sinais-termo do campo do patrimônio cultural em Libras, alocado no Núcleo de Estudo e Pesquisa da Variação Linguística da Libras ( Núcleo Varlibras); uma em HD externa sob guarda do coordenador do projeto; e uma em disco rígido sob responsabilidade dos colaboradores. 
O coordenador do projeto não assume aprioristicamente uma forma mais adequada para a organização dos dados, pois tal organização deverá emergir a partir da reflexão crítica sobre o próprio desenvolvimento do projeto. Ainda assim, sugere-se aqui alguns encaminhamentos possíveis. Os dados serão organizados com base nas regras lexicográficas proposta por Castro Júnior (2014). O processo de formação envolve tanto aspectos teóricos quanto aspectos práticos do trabalho de constituição do inventário.

Na consultoria técnica e de capacitação continuada, os participantes tiveram, durante todo o período em que foi desenvolvido o projeto, uma assessoria didática Linguística em Libras, que auxiliou na identificação e resolução dos problemas que surgirem no decorrer do projeto. Considerando as dimensões geográficas do Distrito Federal e de Goiás no Brasil, foi necessário empregar algumas estratégias da educação à distância no que tange à formação teórica do projeto, para fins de otimização dos recursos.

Em particular, foi criado um espaço virtual de interação e aprendizagem, utilizando a plataforma Aprender da Universidade de Brasília - UnB, onde foram postados os materiais videográficos e textos relevantes do projeto, com fóruns de discussão abertos para a discussão e o esclarecimento de dúvidas. Tanto a produção de materiais EaD quanto a realização de atividades à distância foram feitos pelos professores de Libras e os colaboradores, fazendo uso da infraestrutura oferecida pela UnB por meio do Estúdio de Registros de Sinais-termo do Núcleo de Estudo e Pesquisa da Variação Linguística da Libras - Varlibras. 
A formação presencial, na UnB em Brasília no campus do Plano Piloto, foi realizada após uma preparação prévia mínima dos participantes com os materiais disponíveis nesse ambiente virtual. Tal formação envolveu a realização efetiva de todas as etapas do processo de constituição do inventário (coleta, arquivamento e disponibilização dos dados) ao longo dos meses de abril e setembro do ano de 2016, sob supervisão da equipe coordenadora do projeto.

A valorização de aspectos práticos do projeto nos encontros de formação presencial, além de contribuir para otimização de recursos, fortaleceu o próprio preparo dos colaboradores, que retornaram aos seus respectivos espaços de atuação com uma experiência prévia concreta de todos os procedimentos que envolverão a coleta, organização e transcrição dos dados.

Além disso, foi aproveitada a inserção dos dados coletados e validados no inventário dos sinais-termo no aplicativo 'Portal do Patrimônio', para divulgar e apresentar como produto ao utilizar um espaço visual, com diversas possibilidades e funções. Para as filmagens, foram montados estúdios volantes em Brasília e em Alto Paraíso no Núcleo Varlibras

A equipe de coleta dos dados teve: 1 colaborador da equipe de coordenação e 2 bolsistas de extensão. Ao colaborador coube a tarefa de condução de toda a entrevista, enquanto ao bolsista de extensão coube a tarefa de apoio na montagem e desmontagem do estúdio volante, bem como apoio na supervisão técnica de todo o processo de gravação e arquivamento no local. O estúdio volante contou com 1 filmadora para captar as 
informações registradas. Teve 1 notebook, que serviu de base para a sua produção, e o colaborador fez o registro de informações pertinentes às sessões de gravação. Os postes de luz, bem como o tecido de lycra que serviu de plano de fundo das gravações, teve como objetivo garantir condições ótimas de visualização dos sinalizadores. As câmeras foram posicionadas de acordo com configurações espaciais previamente testadas e planejadas de acordos com regras lexicográficas para o registro de sinaistermo proposta por Castro Júnior (2014).

As entrevistas com os sinalizantes foram compostas pelas seguintes atividades o colaborador buscou registrar os sinais-termo do campo patrimônio cultural em Libras, envolvendo registros de aspectos como: a explicação da criação do sinal-termo, os sinais-termo propostos e o entendimento do conceito do sinal-termo pelo Surdo. Foi priorizada a comunicação em Libras em todo o processo do projeto, pois sem isso o Surdo não terá sua integração com o mundo acadêmico, e os não-surdos não aprenderão a Libras. O corpo e as mãos dos Surdos traduzem espontaneamente o seu pensamento, daí a importância das pessoas que convivem com o Surdo terem ao menos um conhecimento mínimo da língua de sinais. Por outro lado, o Surdo será sempre motivado a conhecer a Língua Portuguesa, numa troca recíproca, pois só há comunicação quando a linguagem é compreendida e tem significado.

A Libras é uma língua de modalidade visual-espacial, baseada no uso de todo o corpo e do espaço diante do corpo para sua comunicação, por isso oferece possibilidades aos Surdos de se expressarem e, assim, desenvolverem o seu potencial, plenamente, de uma forma que as línguas

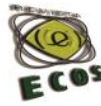


orais não permitem. Dessa forma, podemos perceber que a diferença desta proposta, baseada no princípio de acessibilidade em Libras, se dá de maneira inversa, em que a comunidade acadêmica da UnB é que se integrou na comunicação de Libras com os Surdos e com a comunidade abrangida. Essa preocupação se deve ao fato de que a universidade, de modo geral, tem as condições necessárias para possibilitar a comunicação em Libras, mas devido a Libras ser uma área nova foi necessário a sua inserção nas atividades de ensino, pesquisa e extensão. A intenção deste projeto foi possibilitar um espaço onde os alunos de graduação e pós-graduação possam se conectar com o uso da Libras, terem acesso às informações disponíveis sobre os Surdos, sobre a Libras, bem como, das possibilidades de serem inseridos e despertarem o interesse de ingressar na comunidade Surda.

Os Surdos, por sua vez, ao interagir com os aprendizes de Libras, tiveram acesso a informações de modo geral da comunidade acadêmica, que constantemente, são comunicadas na Língua Portuguesa. Outro diferencial deste projeto foi a capacitação e assessoria aos participantes, que foi feita antes e durante todo o processo. Dessa forma, tiveram todas as condições para se sentirem preparados e apoiados durante todo o desenvolvimento do projeto. No programa de orientação, foi previsto o desenvolvimento dos seguintes conteúdos, considerados pelos especialistas da área de Libras necessários para o bom andamento do projeto: i) Abordagens e aspectos linguísticos da Libras; Língua de sinais e aspectos didáticos - pedagógicos; Os artefatos tecnológicos para a comunicação em Libras; ii) Cidadania e Libras: abordagem cultural e conceitos relativos ao campo do Patrimônio 
Cultural e iii) Aspectos legais: o direito da pessoa surda, garantias constitucionais no Brasil, legislação ordinária no Brasil e outras proteções legais em torno da acessibilidade Linguística e do registro da Diversidade Linguística em Libras.

Os procedimentos éticos demonstraram que o desenvolvimento de um inventário da Libras é um projeto que só pode ser realizado com o envolvimento direto da comunidade Surda. Para isso, no decorrer do ano de 2016, foi possível dar início a esse empreendimento com uma consulta direta a associações e outras organizações de Surdos a fim de se esclarecer os objetivos e a importância deste projeto para a educação de Surdos no Brasil. Além disso, a coordenação do projeto esteve aberta para conhecer os interesses da comunidade Surda com relação aos tipos de textos ou temas que julgam mais relevantes de serem documentadas em torno do campo do patrimônio Linguístico e cultural, as formas de procedimento para a coleta dos dados, e às expectativas com relação ao tipo de devolutiva que o projeto pode oferecer à comunidade Surda brasileira.

Por fim, a terceira fase de outubro a dezembro de 2016, buscou obter informações relativas aos critérios de avaliação do projeto que foram discutidos durante as reuniões ou por meio de outras estratégias, que foram necessárias, pelo coordenador do projeto. Foi dada atenção especial para a elaboração do relatório e do registro de todas atividades desenvolvidas pela equipe para a elaboração de dados finais para a apresentação de resultados. No próximo item vamos discutir as contribuições esperadas a partir dos resultados do projeto do Inventário Nacional de Sinais-termo do Campo do Patrimônio Cultural em Libras na educação de Surdos. 


\section{Contribuições esperadas na educação de Surdos com o Inventário Nacional de sinais-termo do Campo do Patrimônio Cultural}

As contribuições esperadas na educação de Surdos com a realização do Inventário Nacional de Sinais-termo do Campo do Patrimônio Cultural em Libras são: i) Análise da realidade atual de acesso e de comunicação por meio da Libras em diferentes eixos, tanto no aspecto quantitativo, em relação à quantidade de informações transmitidas pela Língua Portuguesa, passadas para a Libras, como em relação à diminuição do prejuízo linguístico para a comunidade Surda pela falta de informações em Libras quanto no aspecto qualitativo, que diz respeito à avaliação da proposta do projeto sobre as mudanças que o uso de tecnologias da informação e comunicação operam no ensino e na melhoria da qualidade de aprendizagem na graduação e na reestruturação da Universidade, e constatação se o projeto contribuiu para o avanço do conhecimento. ii) Avaliar os aspectos positivos e negativos no decorrer do desenvolvimento do projeto e os impactos causados. iii) Avaliar os impactos sociais e Linguísticos decorrentes da aplicação do projeto nas comunidades abrangidas e enumerar as alternativas para eventuais aspectos negativos, quando cabíveis.

Vale lembrar que este projeto caminha em paralelo à formalização de trabalhos já realizados na área de Libras, cuja natureza é efetivamente de assessoramento, consultoria e formação. Por meio dos resultados satisfatórios do Inventário de Sinais-termo do Campo do Patrimônio Cultural em Libras, foi possível uma ampliação do projeto no Inventário 
Nacional de Sinais-termo do Campo do Patrimônio Artístico, Cultural e Histórico em Libras a ser desenvolvido por diferentes instituições parceiras e que terá um papel fundamental para elaboração dos planos de ações futuros que contribua na educação de Surdos no uso da Libras como estratégia didática no ensino/pesquisa/extensão.

\section{Considerações finais}

Assumir uma atitude inovadora e transformadora da realidade social e Linguística implica ampliar e fortalecer a integração entre ensino, pesquisa e extensão principalmente quando se trata de acessibilidade e de registro da Diversidade Linguística e do Patrimônio Literário Nacional.

É preciso pensar e discutir a integração destes três eixos, principalmente por meio da extensão na formação de alunos de graduação e pós-graduação das diversas instituições de ensino do Brasil, por meio de conhecimentos teóricos e práticos correlacionados à área da Linguística com foco no registro de sinais-termo no campo do patrimônio cultural em Libras.

Deste modo, a análise da realidade atual de acesso e de comunicação por meio da Libras deve buscar a diminuição do prejuízo linguístico para a comunidade Surda pela falta de informações em Libras quanto no aspecto qualitativo, que diz respeito à avaliação da proposta do projeto sobre as mudanças que o uso de tecnologias da informação e comunicação operam no ensino e na melhoria da qualidade de aprendizagem na graduação e pósgraduação, em busca da constatação se o projeto contribui ou não para a 
acessibilidade Linguística, Cultural e Literária, tanto no ensino, na pesquisa e na extensão.

Assim, considerando o universo e a complexidade da formação humana, pressupõe-se a necessidade de viabilizar aprendizagens significativas, produzidas a partir da aquisição do conhecimento socialmente elaborado e contextualizado em língua de sinais pelos especialistas da área. Formação essa capaz de proporcionar aos profissionais intervenções na e sobre a realidade, construídas com autonomia e competência para um fazer vinculado à prática social e Linguística, geradora de novos saberes e novos fazeres.

Além desta relação, podemos elencar como produto de todo este processo o registro da língua - Libras no Portal do Patrimônio, resultado da interdisciplinaridade e que irá retornar enquanto material didático para os usos nas aulas de Libras de diversas instituições que ofertam a disciplina Libras.

\section{Referências}

ASSOCIAÇÃO BRASILEIRA DE NORMAS TÉCNICAS (ABNT). NBR 9050: Acessibilidade a edificações, mobiliário, espaços e equipamentos urbanos. 2004. Rio de Janeiro, 1994.

BRASIL. Constituição (1988). Constituição da República Federativa do Brasil: promulgada em 5 de outubro de 1988. Organização do texto: Juarez de Oliveira. 4. Ed.

São Paulo: Saraiva, 1990 
. Estatuto da Cidade: Lei 10.257/2001 que estabelece diretrizes gerais da política urbana. Brasília, Câmara dos Deputados, 2001, $1^{\text {a }}$ Edição.

Lei n. 8.080, de 19 de setembro de 1990. Diário oficial da União. Brasília, DF, 20 set 1990, p.18055.

. Lei $n^{\circ} .7 .853$, de 24 de Outubro de 1989. Dispõe sobre o apoio às pessoas portadoras de deficiência, sua integração social, sobre a Coordenadoria Nacional para Integração da Pessoa Portadora de Deficiência - Corde institui a tutela jurisdicional de interesses coletivos ou difusos dessas pessoas, disciplina a atuação do Ministério Público, define crimes, e dá outras providências. Diário Oficial [da República Federativa do Brasil], Brasília.

. Lei ${ }^{\circ}$. 10.098, de 19 de Dezembro de 2000. Estabelece normas gerais e critérios básicos para a promoção da acessibilidade das pessoas portadoras de deficiência ou com mobilidade reduzida, e dá outras providências. Diário Oficial [da República Federativa do Brasil], Brasília. . Lei $n^{\circ}$. 10.048, de 08 de Novembro de 2000. Dá prioridade de atendimento às pessoas que especifica, e dá outras providências. Diário Oficial [da República Federativa do Brasil], Brasília.

. Decreto-lei n. 5.626, de 22 de dezembro de 2005. Regulamenta a Lei n. 10436 de 22/04/2002 e o art. 18 da Lei 10.098 de 19/12/2000. Lei n. 10.436 de 22 de Abril de 2002. Oficializa a Libras. CASTRO JÚNIOR, Gláucio de. Variação regional lexical na Língua de Sinais Brasileira: inteorizando a prática educativa. Projeto de iniciação científica desenvolvido na Universidade de Brasília - UnB. 2009. 
Projeto Varlibras. Tese de Doutorado em Linguística apresentada ao Programa de Pós-graduação em Linguística da Universidade de Brasília - UnB. Novembro, 2014.

FERREIRA, Aurélio Buarque de Holanda. Novo Dicionário da língua portuguesa. 3. ed. Curitiba: Positivo, 2009.

KLIMA, Edward S.; BELLUGI, Úrsula. The signs of Language. Cambridge Harvard University Press, 1979.

MICHAELIS. Moderno dicionário da língua portuguesa. 2. ed. São Paulo: Melhoramentos, 2000.

SASSAKI, R. Inclusão: o paradigma do século 21. Revista da Educação Especial. ME/SEESP. Brasília/DF, v.1, n.1, 2005.

Inclusão no lazer e turismo: em busca da qualidade de vida. São Paulo: Áurea, 2003.

. Turismo inclusivo. Revista Nacional de Reabilitação. São Paulo, ano V, n. 28, p. 4-5, set./out. 2002.

QUADROS, Ronice Muller de; KARNOPP, Lodenir Becker. Língua de sinais brasileira: estudos linguísticos. Porto Alegre: Artmed, 2004.

SACKS, O. Vendo vozes: uma viagem ao mundo dos surdos. São Paulo: Cia das Letras, 1998. 